\title{
PENGARUH PELATIHAN TERHADAP KOMPETENSI KARYAWAN PT. LEN INDUSTRI (PERSERO) BANDUNG
}

\author{
Putu Ifo Yuda Wisastra ${ }^{(1)}$ \\ Ella Jauvani Sagala ${ }^{(2)}$ \\ (1), (2)Fakultas Ekonomi dan Bisnis, Universitas Telkom \\ email: ifoyuda@gmail.com
}

\begin{abstract}
ABSTRAK
Penelitian ini bertujuan untuk menganalisis pengaruh pelatihan terhadap kompetensi karyawan yang dilakukan di PT. Len Industri (Persero) Bandung. Penentuan besarnya sampel pada penelitian ini menggunakan metode teknik Slovin dengan tingkat kesalahan sebesar 5\%. Teknik analisis data yang digunakan adalah Path Analysis yang diolah dengan software SPSS ver.20 for windows. Data dikumpulkan melalui kuesioner terhadap 192 responden karyawan PT. Len Industri (Persero) Bandung. Hasil pengolahan data menunjukkan bahwa variabel pelatihan secara simultan berpengaruh signifikan terhadap kompetensi karyawan, namun secara parsial tidak berpengaruh signifikan terhadap kompetensi karyawan. Variabel yang tidak berpengaruh signifikan tersebut yaitu variabel materi pelatihan dan peserta pelatihan.
\end{abstract}

Kata kunci : sumber daya manusia, pelatihan, kompetensi

\begin{abstract}
This study aimed to analyze the influence of training on employee's competency. This study was conducted at PT. Len Industri (Persero) Bandung. The sampling was using Slovin's techniques with error rate $5 \%$.The data analysis was using Path Analysis for this research and processed by using SPSS software ver.20 for windows. Data obtained by questionnaires to 192 employee respondents of PT. Len Industri (Persero) Bandung. The result showed that training variables had a significant influence on employee's competency with simultaneously. But in partially, there's didn't have a significant influence on the employee's competency. The variables that didn't have a significant influence were training materials and trainees.
\end{abstract}

Keywords : human resources, training, competency

\section{PENDAHULUAN}

Berdasarkan riset yang dilakukan oleh lembaga riset Aberdeen (2013) di Boston, Amerika Serikat mengenai Human Capital Management Trends, menyatakan sumber daya manusia (SDM) merupakan faktor penting bagi kelangsungan perusahaan/organisasi dalam melakukan bisnis. Peran SDM sangat diperlukan, tanpa adanya peran dari SDM tersebut, maka akan berpengaruh ke penurunan performansi dalam mencapai tujuan yang telah ditetapkan oleh perusahaan.

Peran teknologi merupakan faktor pendukung dalam mencapai tujuan perusahaan. Suatu perusahaan memiliki teknologi paling canggih tetapi tidak dapat digunakan secara maksimal oleh orangorang di dalamnya, maka teknologi yang mendukung aktivitas bisnis tersebut akan menjadi sia-sia (Fedderke, 2005). Berdasarkan hal tersebut, SDM dan kemajuan teknologi harus berjalan secara bersamaan agar penggunaan teknologi oleh suatu perusahaan dapat dilaksanakan secara optimal. Salah satu cara agar karyawan memiliki keterampilan dan wawasan yang luas adalah dengan memberikan pendidikan dan pelatihan yang diselenggarakan oleh perusahaan. Penelitian mengenai hal tersebut dilakukan oleh Dirani (2012) di Georgia, Amerika Serikat.

Penelitian Naweed dan Ambrosetti (2015), menunjukkan bahwa peserta trainee yang telah dimentoring berdampak pada peningkatan pembelajaran mereka dan kurangnya mentoring merupakan cara untuk menjelaskan suatu permasalahan industri. Voegtlin et al., (2015), menunjukkan bahwa pelatihan yang dilakukan perusaaan berpengaruh terhadap pemberdayaan karyawannya. Hasil serupa dinyatakan Merwe dan Sloman (2014), bahwa pelatihan yang dilakukan kepada peserta trainee memberikan dampak yang signifikan terhadap kompetensi dan benefit untuk organisasi.

Undang-Undang di Indonesia yang mengatur mengenai pelatihan dan kompetensi adalah Undang Undang Ketenagakerjaan pasal 1 ayat 9 dan Undang-Undang No. 13 tentang ketenagakerjaan tahun 2003. Pelatihan kerja adalah keseluruhan kegiatan untuk memberi, memperoleh, meningkatkan, 
serta mengembangkan kompetensi kerja, produktivitas, disiplin, sikap, dan etos kerja pada tingkat keterampilan dan keahlian tertentu sesuai dengan jenjang dan kualifikasi jabatan atau pekerjaan. Pengusaha bertanggung jawab atas peningkatan dan/atau pengembangan kompetensi pekerjanya melalui pelatihan kerja.

Aspek SDM merupakan aspek penting dalam organisasi dalam mencapai tujuan perusahaan dan sangat berperan dalam perkembangan dan pencapaian organisasi bisnis (Endang Setyaningdyah dkk., 2013). SDM juga merupakan aset yang tidak pernah tergantikan pada organisasi dalam mengoperasikan teknologi yang mendukung dalam pencapaian tujuan perusahaan (Sunarta, 2008). SDM akan memiliki kualitas yang lebih baik jika suatu organisasi memberikan program pelatihan kepada para pegawainya. Penelitian oleh Zuana dkk., (2014) mendukung hal tersebut,yang menyatakan bahwa pelatihan kerja berpengaruh terhadap prestasi kerja karyawan. Kandou (2013) juga menyatakan bahwa adanya hubungan yang positif antara pelatihan dengan produktivitas kerja karyawan.

Hidayat (2015) menyatakan bahwa orangorang Indonesia banyak yang pandai dan terampil, tetapi tidak tersertifikasi. Persaingan dunia kerja, sangat ketat dengan diberlakukannya Masyarakat Ekonomi ASEAN (MEA). Sertifikasi merupakan modal utama dalam meningkatkan daya saing antar pegawai ketika akan melamar pekerjaan.

Survei yang dilakukan oleh firma konsultasi kelas dunia, The Boston Consulting Group (BCG), bertajuk BCG ASEAN Economic Integration Survey yang dikutip dari www.swa.co.id, mengungkapkan bahwa Indonesia adalah satusatunya negara yang menghasilkan persepsi responden bahwa MEA sebagai suatu ancaman yang serius dalam proporsi yang cukup signifikan.

PT Len melakukan peningkatan kualitas SDM pegawai dengan mengadakan pendidikan yang telah menyelenggarakan 72 program pelatihan yang diikuti oleh 604 peserta selama 1362 hari,dari semua level fungsional. Pelatihan ditujukan sebagai bentuk implementasi kebijakan perusahaan yang ingin memiliki SDM yang berkualitas dan berkompeten dibidang masing-masing.

Berdasarkan hasil wawancara sebagai studi awal dengan bagian PIC (Person In Charge) atau penanggungjawab pendidikan dan pelatihan (diklat) didapatkan fakta bahwa beberapa karyawannya PT Len sudah memiliki sertifikasi,baik sertifikasi nasional maupun internasional. Juga saat ini PT Len masih belum memiliki kompetitor untuk perusahaan yang sejenis di Indonesia melainkan kompetitor PT Len lebih ke arah global dan tergantung dari proyek yang dikerjakannya, karena tiap-tiap proyek yang akan dikerjakan oleh PT Len akan berbeda pula kompetitornya. Walaupun PT Len belum memliki kompetitor di Indonesia, mereka tetap berusaha untuk meningkatkan kompetensi karyawannya dengan mengadakan beberapa pelatihan untuk bisa bersaing secara global.

PT Len telah membuat SKI (Sasaran Kerja Individu) yang mencakup hasil kerja dan proses kerja dalam menilai kompetensi karyawannya. Untuk hasil kerja, beberapa indikator yang dinilai oleh PT Len adalah; pengetahuan kerja, kualitas kerja, kelengkapan, kecepatan, ketelitian kerja dan ide-ide. Sedangkan proses kerja, indikator yang dinilai adalah; integritas, inisiatif, kerjasama, kemandirian, organisasi kerja dan pemanfaatan waktu (lihat Tabel 1).

Tabel 1. Kriteria SKI PT Len Industri (Persero) Bandung

\begin{tabular}{cc}
\hline Kriteria & Predikat \\
\hline $0 \%-64 \%$ & Cukup \\
$65 \%-84 \%$ & Baik \\
$85 \%-94 \%$ & Sangat Baik \\
$95 \%-100 \%$ & Istimewa \\
\hline
\end{tabular}

Sumber: Data Internal PT Len Industri (Persero) Bandung 2016

Penilaian SKI dari pegawai yang ada di PT Len Industri (Persero) Bandung yang dapat dilihat pada Tabel 2.

Tabel 2. Penilaian SKI Pegawai PT Len Industri (Persero) Bandung

\begin{tabular}{|c|c|c|c|c|c|c|c|}
\hline \multirow[b]{2}{*}{ Tahun } & \multicolumn{6}{|c|}{ Kriteria } & \multirow{2}{*}{$\begin{array}{c}\text { Total } \\
\text { Pegawai }\end{array}$} \\
\hline & $\begin{array}{c}\text { Tidak } \\
\text { Mengumpulkan }\end{array}$ & $\begin{array}{l}\text { Belum } \\
\text { Masuk }\end{array}$ & Cukup & Baik & $\begin{array}{c}\text { Sangat } \\
\text { Baik }\end{array}$ & Istimewa & \\
\hline 2013 & 13 & 67 & 0 & 3 & 274 & 13 & 370 \\
\hline 2014 & 13 & 6 & 0 & 5 & 318 & 28 & 370 \\
\hline 2015 & 6 & 7 & 1 & 4 & 325 & 27 & 370 \\
\hline
\end{tabular}

Sumber: Data Internal PT Len Industri (Persero) Bandung 2016 
Data tersebut menunjukkan jumlah pegawai PT Len Industri (Persero) Bandung tahun 2013 sampai tahun 2015 tidak mengalami perubahan, yakni sebanyak 370 pegawai. Jumlah pegawai yang belum mengumpulkan penilaian SKI ditahun 2013 tergolong cukup banyak yaitu sebesar 67 pegawai $(18,11 \%)$, namun angka ini bisa ditekan oleh PT Len Industri ditahun 2014 menjadi 6 pegawai (1,62\%) yang belum mengumpulkan penilaian SKInya. Pada tahun 2015 jumlah pegawai yang belum mengumpulkan SKI meningkat sebanyak 1 (satu) pegawai dari tahun sebelumnya sehingga total pegawai yang belum mengumpulkan SKI ditahun 2015 sebanyak 7 pegawai.

Kriteria pegawai PT Len Industri secara keseluruhan termasuk dalam kategori sangat baik, hal ini dapat dilihat pada Tabel 2 dimana jumlah pegawai berkriteria sangat baik dari tahun 2013 hingga 2014 mengalami peningkatan sebesar 11,89\% dan ditahun 2015 meningkat sebesar 1,89\%.

\section{METODE}

Penelitian ini merupakan penelitian kuantitatif. Menurut Sugiyono (2013:8) penelitian kuantitatif dapat diartikan sebagai metode penelitian yang berlandaskan positivisme, digunakan untuk meneliti pada populasi atau sampel tertentu, pengumpulan data menggunakan instrumen penelitian, analisis data bersifat kuantitatif/statistik dengan tujuan untuk menguji hipotesis yang telah ditetapkan. Penelitian ini merupakan penelitian deskriptif dan kausal.
Penelitian deskriptif biasanya dilakukan saat peneliti sudah mengetahui faktor atau variabel untuk mengukur suatu objek atau bidang tetapi belum mengetahui hubungan antar faktor atau variabel tersebut. Tujuan dari penelitian deskriptif adalah menggambarkan karakteristik atau fungsi dari suatu variabel atau beberapa variabel dalam suatu situasi (Indrawati, 2015:115). Menurut Amirullah (2013:12) studi kausal merupakan penelitian yang tujuan utamanya adalah untuk mencari hubungan sebab akibat.

Tipe penyelidikan penelitian ini dikategorikan sebagai penelitian korelasional. Korelasi merupakan istilah yang digunakan untuk mengukur kekuatan hubungan antar variabel (Supardi, 2013:165). Berdasarkan keterlibatan peneliti, dalam penelitian ini peneliti tidak mengintervensi data, yang artinya bahwa peneliti tidak mengubah atau memanipulasi variabel tertentu untuk mempelajari akibat dari manipulasi tersebut terhadap variabel terkait yang diteliti (Sekaran, 2006:167). Unit analisis dalam penelitan ini adalah organisasi, yaitu pada PT Len Industri (Persero) Bandung.

Penelitian ini menggunakan metode cross sectional. Metode cross sectional merupakan pengumpulan data yang dilakukan dalam suatu periode, kemudian data tersebut diolah, dianalisi, dan kemudian ditarik kesimpulannya (Indrawati, 2015:118). Secara ringkas, karakteristik penelitian dapat dilihat pada Tabel 3 berikut:

Tabel 3. Karakteristik Penelitian

\begin{tabular}{lll}
\hline No. & Karakteristik Penelitian & \multicolumn{1}{c}{ Jenis } \\
\hline 1. & Berdasarkan metode & Kuantitatif \\
2. & Berdasarkan tujuan & Deskriptif dan Konklusif(Kausal) \\
3. & Berdasarkan tipe penyelidikan & Korelasional \\
4. & Berdasarkan keterlibatan peneliti & Tidak mengintervensi data \\
5. & Berdasarkan unit analisis & Organisasi \\
6. & Berdasarkan waktu pelaksanaan & Cross Section \\
\hline
\end{tabular}

Sumber: Data primer diolah

\section{Populasi}

Populasi merupakan generalisasi yang terdiri atas obyek/subyek yang mempunyai kualitas dan karakteristik tertentu yang ditetapkan oleh peneliti untuk dipelajari dan kemudian ditarik kesimpulannya. (Sugiyono, 2013:80). Obyek penelitian dalam penelitian ini adalah PT Len Industri (Persero) Bandung. Populasi dari penelitian ini adalah seluruh pegawai yang pernah mengikuti program pelatihan yang diselenggarakan oleh PT Len Industri (Persero) Bandung.

\section{Sampel}

Menurut Sugiyono (2013:81) sampel merupakan bagian dari jumlah dan karakteristik yang dimiliki oleh populasi tersebut. Bila populasi besar, maka sampel dapat digunakan jika populasinya tidak mungkin dipelajari semua. Teknik pengambilan sampel pada penelitian ini menggunakan teknik probability sampling yaitu simple random sampling. Menurut Sugiyono (2013:82) probability samping merupakan teknik pengambilan sampel yang memberikan peluang yang sama bagi setiap 
Tabel 4. Populasi Penelitian

\begin{tabular}{clc}
\hline No & Unit Kerja & Jumlah Pegawai \\
\hline 1. & Korporasi & 137 \\
2. & Unit Bisnis & 119 \\
3. & Unit Pengembangan & 47 \\
4. & Unit Produksi & 67 \\
\hline & Total & 370 \\
\hline
\end{tabular}

Sumber: Data Internal PT Len Industri (Persero) 2016

unsur (anggota) populasi untuk dipilih menjadi anggota sampel. Sedangkan simple random sampling adalah pengambilan anggota sampel dari populasi dilakukan secara acak tanpa memperhatikan yang ada dalam populasi itu.

Pada penelitian, ini sampel ditentukan dengan menggunakan rumus Slovin. Dalam menentukan ukuran sampel penelitian, Slovin memasukkan unsur kelonggaran ketidaktelitian karena kesalahan pengambilan sampel yang masih dapat ditoleransi. Nilai toleransi ini dinyatakan dalam persentase. (Sanusi, 2011:101).

$$
\begin{aligned}
& n=\frac{N}{1+N e^{2}} \\
& \quad \text { Sehingga, } \\
& n=\frac{370}{1+370(0,05)^{2}}=192,207 \approx 192
\end{aligned}
$$

Berdasarkan perhitungan Slovin, maka sampel yang digunakan pada penelitian ini sebanyak 192 sampel. Validitas

Hasil penelitian yang valid akan didapatkan bila terdapat kesamaan antara data yang terkumpul dengan data yang sesungguhnya terjadi pada obyek yang diteliti. Instrumen yang valid berarti alat ukur yang digunakan untuk mendapatkan data (mengukur) itu valid. Valid berarti instrumen tersebut dapat digunakan untuk mengukur apa yang seharusnya diukur.

Untuk menguji validitas instrumen penelitian digunakan korelasi Pearson Product Moment (Sanusi, 2011:77). Uji validitas pada penelitian ini menggunakan bantuan software SPSS (Statistical Program of Social Science)ver.20 menggunakan nilai $\mathrm{n}=30$ dan tingkat signifikansi sebesar 0,05 sehingga nilai $r_{\text {Tabel }}$ yang diperoleh sebesar 0,361. Nilai $\mathrm{r}_{\text {hitung }}$ diambil dari output SPSS Cronbach Alpha pada kolom Correlated Item-Total Correlation.

Tabel 5. Hasil Uji Validitas Pelatihan (X)

\begin{tabular}{llcc}
\hline Pernyataan & $\mathrm{r}_{\text {hitung }}$ & $\mathrm{r}_{\text {Tabel }}$ & Keterangan \\
\hline 1 & 0,398 & 0,361 & Valid \\
2 & 0,630 & 0,361 & Valid \\
3 & 0,712 & 0,361 & Valid \\
4 & 0,438 & 0,361 & Valid \\
5 & 0,511 & 0,361 & Valid \\
6 & 0,535 & 0,361 & Valid \\
7 & 0,444 & 0,361 & Valid \\
8 & 0,656 & 0,361 & Valid \\
9 & 0,577 & 0,361 & Valid \\
10 & 0,568 & 0,361 & Valid \\
11 & 0,670 & 0,361 & Valid \\
12 & 0,429 & 0,361 & Valid \\
13 & 0,392 & 0,361 & Valid \\
14 & 0,656 & 0,361 & Valid \\
15 & 0,609 & 0,361 & Valid \\
16 & 0,688 & 0,361 & Valid \\
17 & 0,586 & 0,361 & Valid \\
18 & 0,750 & 0,361 & Valid \\
19 & 0,413 & 0,361 & Valid \\
20 & 0,728 & 0,361 & Valid \\
21 & 0,640 & 0,361 & Valid \\
22 & 0,626 & 0,361 & Valid \\
23 & 0,454 & 0,361 & Valid \\
\hline
\end{tabular}

Sumber: Hasil pengolahan data penelitian 
Berdasarkan Tabel 5 menunjukkan bahwa pengujian terhadap 23 butir pernyataan dinyatakan valid karena $r_{\text {hitung }}>r_{\text {Tabel }}$ sehingga bisa digunakan sebagai instrumen untuk analisis selanjutnya. Hasil validitas untuk variabel kompetensi dapat dilihat pada Tabel 6

Tabel 6. Hasil Uji Validitas Kompetensi (Y)

\begin{tabular}{lccc}
\hline Pernyataan & $\mathrm{r}_{\text {hitung }}$ & $\mathrm{r}_{\text {Tabel }}$ & Keterangan \\
\hline 24 & 0,745 & 0,361 & Valid \\
25 & 0,377 & 0,361 & Valid \\
26 & 0,632 & 0,361 & Valid \\
27 & 0,542 & 0,361 & Valid \\
28 & 0,482 & 0,361 & Valid \\
29 & 0,499 & 0,361 & Valid \\
30 & 0,364 & 0,361 & Valid \\
31 & 0,720 & 0,361 & Valid \\
32 & 0,481 & 0,361 & Valid \\
33 & 0,466 & 0,361 & Valid \\
34 & 0,550 & 0,361 & Valid \\
35 & 0,426 & 0,361 & Valid \\
36 & 0,380 & 0,361 & Valid \\
37 & 0,716 & 0,361 & Valid \\
38 & 0,574 & 0,361 & Valid \\
39 & 0,594 & 0,361 & Valid \\
40 & 0,517 & 0,361 & Valid \\
\hline
\end{tabular}

Sumber: Hasil pengolahan data penelitian

Berdasarkan Tabel 6 menunjukkan bahwa pengujian terhadap 17 butir pernyataan dinyatakan valid karena $r_{\text {hitung }}>r_{\text {Tabel }}$ sehingga bisa digunakan sebagai instrumen untuk analisis selanjutnya

\section{Reliabilitas}

Menurut Sanusi (2011:80), Reliabilitas adalah suatu alat pengukur yang menunjukkan konsistensi hasil pengukuran sekiranya alat pengukur itu digunakan oleh orang yang sama dalam waktu yang berlainan atau digunakan oleh orang yang berlainan dalam waktu yang bersamaan atau waktu yang berlainan. Secara implisit, reliabilitas ini mengandung objektivitas karena hasil pengukuran tidak terpengaruh oleh siapa pengukurnya. Teknik reliabilitas pada penelitian ini menggunakan rumus alpha.

Zikmund (2010:306) mengemukakan bahwa suatu intrumen alat ukur dapat dikatakan reliabel dan bisa diproses pada tahap selanjutnya apabila nilai Cronbach Alpha 0,6 - 1. Jika instrumen alat ukur memiliki nilai Cronbach Alpha kurang dari 0,6 maka alat ukur tersebut tidak reliabel.

Dalam menguji reliabilitas, peneliti menggunakan bantuan komputer untuk mempermudah dan mengurangi kesalahan dalam mengolah data dengan menggunakan bantuan software Statistical
Program of Social Science (SPSS) ver.20. Hasil uji reliabilitas dapat dilihat pada Tabel 7.

Dari Tabel 7 dapat dilihat bahwa nilai Cronbach's Alpha sebesar 0,939. Karena nilainya lebih besar dari 0,6 maka semua item pernyataan reliabel untuk mengukur variabel pelatihan.

Tabel 7. Hasil Uji Reliabilitas Pelatihan (X) Reliability Statistics

\begin{tabular}{rrr}
\hline Cronbach's Alpha & \multicolumn{2}{c}{ N of Items } \\
\hline .939 & 23
\end{tabular}

Sumber: Hasil pengolahan data penelitian

Tabel 8. Hasil Uji Reliabilitas Kompetensi(Y) Reliability Statistics

\begin{tabular}{lll}
\hline Cronbach's Alpha & N of Items & \\
\hline & .933 & 17
\end{tabular}

Sumber: Hasil pengolahan data penelitian

Berdasarkan Tabel 8, dapat dilihat bahwa nilai Cronbach's Alpha sebesar 0,933. Karena nilainya lebih besar dari 0,6 maka semua item pernyataan reliabel untuk mengukur variabel kompetensi. 


\section{HASIL DAN PEMBAHASAN}

Tabel 9 menunjukkan karakteristik responden yang didominasi oleh jenis kelamin pria sebesar $71 \%$. Kategori usia didominasi oleh usia 26 - 35 tahun sebanyak $47 \%$. Lama bekerja lebih dari 5 tahun sebanyak 36\%. Unit kerja pada penelitian ini didominasi oleh responden yang bekerja pada unit bisnis. Pendidikan terkahir didominasi oleh pendidikan S1 sebesar $43 \%$.

Tabel 9. Karakteristik Responden

\begin{tabular}{|c|c|c|c|}
\hline \multirow{2}{*}{ No. } & \multirow{2}{*}{ Jenis Kelamin } & \multicolumn{2}{|c|}{ Jumlah } \\
\hline & & Orang & Persentase \\
\hline 1 & Pria & 137 & $71 . \%$ \\
\hline 2 & Wanita & 55 & $29 . \%$ \\
\hline Jumlah & & 192 & $100 \%$ \\
\hline \multirow{2}{*}{ No. } & \multirow{2}{*}{ Usia } & \multicolumn{2}{|c|}{ Jumlah } \\
\hline & & Orang & Persentase \\
\hline 1 & $\leq 25$ thn & 76 & $39 \%$ \\
\hline 2 & $26-35$ thn & 90 & $47 \%$ \\
\hline 3 & $36-45$ thn & 7 & $4 \%$ \\
\hline 4 & $>45$ thn & 19 & $10 \%$ \\
\hline Jumlah & & 192 & $100 \%$ \\
\hline \multirow{2}{*}{ No. } & \multirow{2}{*}{ Lama Bekerja } & \multicolumn{2}{|c|}{ Jumlah } \\
\hline & & Orang & Persentase \\
\hline 1 & $<1$ thn & 40 & $21 \%$ \\
\hline 2 & $1-2$ thn & 28 & $15 \%$ \\
\hline 3 & $3-4$ thn & 54 & $28 \%$ \\
\hline 4 & $>5$ thn & 70 & $36 \%$ \\
\hline Jumlah & & 192 & $100 \%$ \\
\hline \multirow{2}{*}{ No. } & \multirow{2}{*}{ Unit Kerja } & \multicolumn{2}{|c|}{ Jumlah } \\
\hline & & Orang & Persentase \\
\hline 1 & Korporasi & 47 & $25 \%$ \\
\hline 2 & Unit Bisnis & 81 & $42 \%$ \\
\hline 3 & Unit Pengembangan & 33 & $17 \%$ \\
\hline 4 & Unit Produksi & 31 & $16 \%$ \\
\hline Jumlah & & 192 & $100 \%$ \\
\hline \multirow{2}{*}{ No. } & \multirow{2}{*}{ Pendidikan Terakhir } & \multicolumn{2}{|c|}{ Jumlah } \\
\hline & & Orang & Persentase \\
\hline 1 & SMU/SMA/Sederajat & 62 & $32 \%$ \\
\hline 2 & Diploma & 46 & $24 \%$ \\
\hline 3 & S1 & 83 & $43 \%$ \\
\hline 4 & $\mathrm{~S} 2$ & 1 & $1 \%$ \\
\hline 5 & S3 & 0 & $0 \%$ \\
\hline Jumlah & & 192 & $100 \%$ \\
\hline
\end{tabular}

Sumber: Hasil pengolahan data penelitian

\section{Hasil Penelitian Analisis Jalur}

Tabel 10. Hasil Uji $t$

\begin{tabular}{|c|c|c|c|c|c|}
\hline \multicolumn{6}{|c|}{ Coefficients $^{\mathrm{a}}$} \\
\hline \multirow[t]{2}{*}{ Model } & \multicolumn{2}{|c|}{$\begin{array}{c}\text { Unstandardized } \\
\text { Coefficients }\end{array}$} & \multirow{2}{*}{$\begin{array}{c}\begin{array}{c}\text { Standardized } \\
\text { Coefficients }\end{array} \\
\text { Beta }\end{array}$} & \multirow[t]{2}{*}{$\mathrm{t}$} & \multirow[t]{2}{*}{ Sig. } \\
\hline & $\mathrm{B}$ & Std. Error & & & \\
\hline (Constant) & 2.793 & .274 & & 10.190 & .000 \\
\hline Tujuan dan Sasaran Pelatihan & .157 & .065 & .190 & 2.416 & .017 \\
\hline Kualitas Pelatih & -.189 & .058 & -.274 & -3.256 & .001 \\
\hline Materi Pelatihan & -.014 & .055 & -.020 & -.245 & .807 \\
\hline Metode Pelatihan & .279 & .058 & .393 & 4.818 & .000 \\
\hline Peserta Pelatihan & .008 & .047 & .012 & .166 & .868 \\
\hline
\end{tabular}

a. Dependent Variable: Kompetensi Karyawan 
Dari Tabel 10, dapat dilihat ada 2 variabel yang tidak signifikan yaitu variabel materi pelatihan $\left(\mathrm{X}_{3}\right)$ dan variabel peserta pelatihan $\left(\mathrm{X}_{5}\right)$ karena nilai sig
$>0.05$. Sesuai dengan ketentuan analisis jalur, maka variabel yang tidak signifikan tersebut dapat dihilangkan(trimming theory) (Sandjojo, 2011:104).

Tabel 11. Model Summary

\begin{tabular}{|c|c|c|c|c|}
\hline \multicolumn{5}{|c|}{ Model Summary } \\
\hline Model & $\mathrm{R}$ & R Square & Adjusted R Square & $\begin{array}{l}\text { Std. Error of the } \\
\text { Estimate }\end{array}$ \\
\hline 1 & $.398^{\mathrm{a}}$ & .159 & .145 & .392751 \\
\hline
\end{tabular}

Dapat dilihat nilai dari R Square $\left(\mathrm{R}^{2}\right)$ sebesar 0.159. Sehingga nilai koefisien determinasi (KD) untuk mengetahui besarnya pengaruh variabel tujuan dan sasaran pelatihan $\left(\mathrm{X}_{1}\right)$, kualitas pelatih $\left(\mathrm{X}_{2}\right)$ dan metode pelatihan $\left(\mathrm{X}_{4}\right)$ secara bersama-sama berpengaruh terhadap kompetensi karyawan (Y) sebesar $15.9 \%$.

Tabel 12. Anova

\begin{tabular}{rlrrrrr}
\hline \multicolumn{7}{c}{ ANOVA $^{\text {a }}$} \\
\hline Model & & Sum of Squares & df & Mean Square & F & \multicolumn{1}{c}{ Sig. } \\
\hline \multirow{3}{*}{1} & Regression & 5.473 & 3 & 1.824 & 11.827 & $.000^{\mathrm{b}}$ \\
& Residual & 29.000 & 188 & .154 & & \\
& Total & 34.473 & 191 & & & \\
\hline
\end{tabular}

a. Dependent Variable: Kompetensi Karyawan

b. Predictors: (Constant), Metode Pelatihan, Tujuan dan Sasaran Pelatihan, Kualitas Pelatih

Dari Tabel ANOVA dapat dilihat nilai probabilitas (Sig.) sebesar 0.000 dimana nilai tersebut lebih kecil dari nilai $\alpha=5 \%$, sehingga $\mathrm{H}_{0}$ ditolak dan $\mathrm{H}_{1}$ diterima yang artinya terdapat pengaruh yang signifikan variabel pelatihan yang terdiri dari tujuan dan sasaran pelatihan, kualitas pelatih dan metode pelatihan terhadap kompetensi karyawan PT. Len Industri (Persero) Bandung.

Tabel 13. Hasil Uji t Trimming

\begin{tabular}{|c|c|c|c|c|c|c|}
\hline \multicolumn{7}{|c|}{ Coefficients $^{\mathrm{a}}$} \\
\hline & \multirow[t]{2}{*}{ Model } & \multicolumn{2}{|c|}{$\begin{array}{l}\text { Unstandardized } \\
\text { Coefficients }\end{array}$} & \multirow{2}{*}{$\begin{array}{l}\text { Standardized } \\
\text { Coefficients } \\
\text { Beta }\end{array}$} & \multirow[t]{2}{*}{$\mathrm{t}$} & \multirow[t]{2}{*}{ Sig. } \\
\hline & & $\mathrm{B}$ & Std. Error & & & \\
\hline & (Constant) & 2.799 & .251 & & 11.137 & .000 \\
\hline \multirow{3}{*}{1} & $\begin{array}{l}\text { Tujuan dan } \\
\text { Sasaran Pelatihan }\end{array}$ & .156 & .061 & 189 & 2.549 & .012 \\
\hline & Kualitas Pelatih & -.193 & .056 & -.279 & -3.439 & .001 \\
\hline & Metode Pelatihan & .276 & .055 & .389 & 5.008 & .000 \\
\hline
\end{tabular}

a. Dependent Variable: Kompetensi Karyawan

Tabel 13 dapat dijelaskan bahwa besarnya pengaruh variabel tujuan dan sasaran pelatihan sebesar 0.189 atau $18.9 \%$ dengan nilai sig $0.012<$ $\alpha(0.05)$ hal ini berarti bahwa hubungan tujuan dan sasaran pelatihan terhadap kompetensi karyawan adalah signifikan. Besarnya pengaruh variabel kualitas pelatih sebesar -0.279 atau $-27.9 \%$ dengan nilai sig $0.001<\alpha(0.05)$ hal ini berarti bahwa hubungan kualitas pelatih terhadap kompetensi karyawan adalah signifikan. Besarnya pengaruh variabel metode pelatihan sebesar 0.389 atau $38.9 \%$ dengan nilai sig $0.000<\alpha(0.05)$ hal ini berarti bahwa hubungan metode pelatihan terhadap kompetensi karyawan adalah signifikan.

Hasil korelasi analisis jalur ditampilkan dalam pada Gambar 1. 


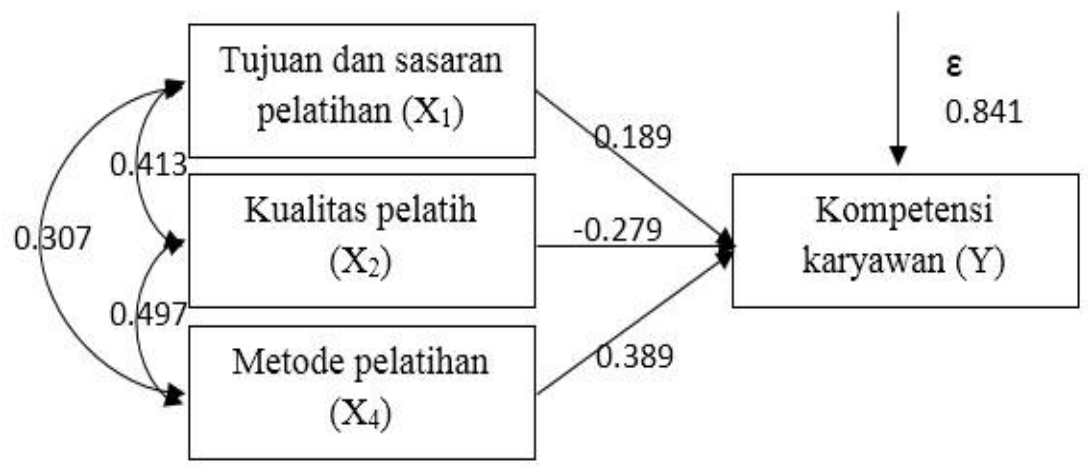

\section{Gambar 1. Diagram Jalur}

Sumber: Hasil pengolahan data penelitian

Persamaan struktural untuk diagram jalur yaitu

$$
Y=0.189 X_{1}-0.279 X_{2}+0.389 X_{4}+\varepsilon
$$

\section{Pengaruh tujuan dan sasaran pelatihan $\left(X_{1}\right)$}

a. Pengaruh langsung:

$$
\begin{aligned}
& =p Y X_{1} \times p Y X_{1} \\
& =0.189 \times 0.189 \\
& =0.035721=\mathbf{3 . 5 7} \%
\end{aligned}
$$

b. Pengaruh yang melalui hubungan korelatif dengan $\mathrm{X}_{\text {, }}$ :

$=p Y X_{1} \times r X_{1} X_{2} \times p Y X_{\text {, }}$

$=0.189 \times 0.413 \times(-0.279)$

$=-0.021778=-\mathbf{2 . 1 8} \%$

c. Pengaruh yang melalui hubungan korelatif dengan $\mathrm{X}_{4}$ :

$=p Y X_{1} \times r X_{1} X_{4} \times p Y X_{4}$

$=0.189 \times 0.307 \times 0.389$

$=0.022571=2.26 \%$

d. Pengaruh $\mathrm{X}_{1}$ ke $\mathrm{Y}$ secara total:

$$
\begin{aligned}
& =0.035721-0.021778+0.022571 \\
& =0.036514=3.65 \%
\end{aligned}
$$

\section{Pengaruh kualitas pelatih $\left(\mathrm{X}_{2}\right)$}

a. Pengaruh langsung:

$$
\begin{aligned}
& =p Y X_{2} \times p Y X_{2} \\
& =-0.279 \times-0.279 \\
& =0.077841=\mathbf{7 . 7 8} \%
\end{aligned}
$$

b. Pengaruh yang melalui hubungan korelatif dengan $\mathrm{X}_{1}$ :

$$
\begin{aligned}
& =p Y X_{2} \times r X_{2} X_{1} \times p Y X_{1} \\
& =-0.279 \times 0.413 \times 0.189 \\
& =-0.021778=-2.18 \%
\end{aligned}
$$

c. Pengaruh yang melalui hubungan korelatif dengan $\mathrm{X}_{4}$ :

$$
\begin{aligned}
& =p Y X_{2} \times r X_{,} X_{4} \times p Y X_{4} \\
& =-0.279 \times 0.497 \times 0.389 \\
& =-0.053940=-\mathbf{5 . 3 9} \%
\end{aligned}
$$

d. Pengaruh $\mathrm{X}$, ke $\mathrm{Y}$ secara total:

$=0.077841-0.021778-0.05394 \mathrm{~d}$

$=0.002123=0.21 \%$

\section{Pengaruh metode pelatihan $\left(\mathbf{X}_{4}\right)$}

a. Pengaruh langsung:

$=p Y X_{4} \times p Y X_{4}$

$=0.389 \times 0.389$

$$
=0.151321=15.13 \%
$$

b. Pengaruh yang melalui hubungan korelatif dengan $\mathrm{X}_{1}$ :

$=p Y X_{4} \times r X_{4} X_{1} \times p Y X_{1}$

$$
=0.389 \times 0.307 \times 0.189
$$

$$
=0.022571=2.26 \%
$$

c. Pengaruh yang melalui hubungan korelatif dengan $\mathrm{X}_{2}$ :

$$
\begin{aligned}
& =p Y X_{4} \times r X_{\Delta} X_{,} \times p Y X_{,} \\
& =0.389 \times 0.497 \times(-0.279) \\
& =-0.053940=-\mathbf{5 . 3 9} \%
\end{aligned}
$$

d. Pengaruh $\mathrm{X}_{4}$ ke $\mathrm{Y}$ secara total:

$$
\begin{aligned}
& =0.151321+0.022571-0.05394 \mathrm{a} \\
= & 0.119952=\mathbf{1 2 . 0 0} \%
\end{aligned}
$$

Pengaruh dari gabungan $\mathrm{X}_{1}, \mathrm{X}_{2}, \mathrm{X}_{4}$ terhadap $\mathrm{Y}$ adalah yang merupakan besarnya $\mathrm{R}$ square Atas dasar perhitungan di atas, dapat dikemukakan halhal berikut.

a. Kekuatan $X_{1}$ secara langsung menentukan perubahan-perubahan $\mathrm{Y}$ sebesar $3.57 \%$ yang melalui hubungannya dengan $X_{2}$ sebesar $2.18 \%$ dan melalui hubungannya dengan $X_{4}$ sebesar $2.26 \%$. Dengan demikian, secara total $\mathrm{X}_{1}$ menentukan perubahan-perubahan $\mathrm{Y}$ sebesar $3.65 \%$.

b. Kekuatan $\mathrm{X}_{2}$ secara langsung menentukan perubahan-perubahan $\mathrm{Y}$ sebesar $7.78 \%$ yang melalui hubungannya dengan $\mathrm{X}_{1}$ sebesar $2.18 \%$ dan melalui hubungannya dengan $X_{4}$ 
sebesar -5.39\%. Dengan demikian, secara total $\mathrm{X}_{2}$ menentukan perubahan-perubahan $\mathrm{Y}$ sebesar $0.21 \%$.

c. Kekuatan $\mathrm{X}_{4}$ secara langsung menentukan perubahan-perubahan $Y$ sebesar $15.13 \%$ yang melalui hubungannya dengan $\mathrm{X}_{1}$ sebesar $2.26 \%$ dan melalui hubungannya dengan $\mathrm{X}_{2}$ sebesar-5.39\%. Dengan demikian, secara total $\mathrm{X}_{4}$ menentukan perubahan-perubahan Y sebesar $12 \%$. d. $\mathrm{X}_{1}, \mathrm{X}_{2}$ dan $\mathrm{X}_{4}$ secara bersama-sama mempengaruhi $\mathrm{Y}$ sebesar. Besarnya pengaruh secara proporsional yang disebabkan oleh variabel lainnya di luar $\mathrm{X}_{1}, \mathrm{X}_{2}$ dan $\mathrm{X}_{4}$ dinyatakan oleh (variabel residu) sebesar .

Untuk lebih jelas pengaruh secara langsung, tidak langsung serta pengaruh totalnya dapat dilihat pada Tabel 14.

Tabel 14. Pengaruh Langsung, Tidak Langsung dan Pengaruh Total

\begin{tabular}{cccccc}
\hline \multirow{2}{*}{ Variabel } & Pengaruh Langsung & \multicolumn{3}{c}{ Pengaruh Melalui } & Pengaruh \\
\cline { 3 - 5 } & & $\mathrm{X}_{1}$ & $\mathrm{X}_{2}$ & $\mathrm{X}_{4}$ & Total \\
\hline $\mathrm{X}_{1}$ & $3.57 \%$ & 0 & $-2.18 \%$ & $2.26 \%$ & $3.65 \%$ \\
$\mathrm{X}_{2}$ & $7.78 \%$ & $-2.18 \%$ & 0 & $-5.39 \%$ & $0.21 \%$ \\
$\mathrm{X}_{4}$ & $15.13 \%$ & $2.26 \%$ & $-5.39 \%$ & 0 & $12.00 \%$ \\
\hline \multicolumn{7}{c}{$R$ square } \\
\hline
\end{tabular}

Sumber: Hasil pengolahan data penelitian

\section{KESIMPULAN DAN SARAN Kesimpulan}

Berdasarkan hasil penelitian dan analisa yang telah dilakukan, maka dapat dibuat beberapa kesimpulan bahwa pelatihan secara simultan berpengaruh positif dan signifikan terhadap kompetensi karyawan PT Len Industri (persero) Bandung. Ini berarti bahwa secara keseluruhan pelatihan yang dilakukan oleh perusahaan sudah terencana dalam meningkatkan kompetensi karyawannya untuk mewujudkan tujuan yang ingin dicapai perusahaan. Namun secara terpisah (parsial), pelatihan berpengaruh tidak signifikan terhadap kompetensi karyawan PT Len Industri (persero) Bandung. Dimensi yang tidak berpengaruh signifikan tersebut adalah dimensi materi pelatihan dan peserta pelatihan. Dimensi yang berpengaruh paling besar terhadap kompetensi karyawan adalah metode pelatihan kemudian disusul oleh tujuan dan sasaran pelatihan serta dimensi yang berpengaruh paling kecil adalah kualitas pelatih.

\section{Saran bagi Perusahaan}

Berdasarkan hasil analisis penelitian yang dilakukan, pelatihan memiliki pengaruh yang kecil terhadap kompetensi karyawan di PT Len Industri (Persero) Bandung, sehingga pihak perusahaan perlu memperhatikan aspek-aspek yang mempengaruhi pelatihan seperti kepemimpinan, kepuasan kerja, kompensasi, kedisiplinan, stres kerja.

Dari hasil penelitian, persentase total pengaruh dari dimensi kualitas pelatih memiliki total pengaruh yang paling kecil dibandingkan dengan dimensi lainnya. Oleh karena itu, PT Len Industri (Persero) Bandung ketika ingin mencari pelatih dalam rangka untuk meningkatkan wawasan para pegawainya harus mencari pelatih yang lebih spesifik atau yang sesuai dengan kepentingan perusahaan serta pelatih yang bersikap profesional.

\section{Saran bagi Penelitian Selanjutnya}

Untuk penelitian selanjutnya, peneliti menyarankan agar menggunakan teknik wawancara tatap muka langsung kepada responden agar bisa memperoleh jawaban yang lebih mendalam, masukan-masukan dari responden yang tidak bisa dilakukan pada penelitian kuantitatif. Mengingat masih banyaknya variabel lain yang mempengaruhi kompetensi karyawan di PT Len Industri (Persero) Bandung, maka disarankan untuk penelitian selanjutnya dapat memasukkan variabel lain tersebut yang berpengaruh terhadap kompetensi karyawan di PT Len Industri (Persero) Bandung.

Penelitian ini menggunakan 5 (lima) dimensi dari kompenen pelatihan yaitu tujuan dan sasaran pelatihan, kualitas pelatih, materi pelatihan, metode pelatihan dan peserta pelatihan serta 1 (satu) variabel kompetensi dari teori Spencer. Untuk penelitian selanjutnya sangat potensial untuk menggunakan pendekatan teori lainnya seperti teori dari Kirkpatrick untuk pelatihan dan teori dari Boyatzis untuk komponen kompetensi. Pengambilan sampel pada penelitian ini mengunakan teknik simple random sampling dimana pengambilan sampel dilakukan 
secara acak berdasarkan frekuensi probabilitas semua anggota populasi. Oleh karena itu, untuk penelitian mendatang penggunaan teknik sampling yang berbeda sangat potensial untuk dilakukan.

Penggunanan metode analisis yang berbeda sangat potensial dilakukan untuk penelitian selanjutnya seperti menggunakan metode analisis SEM (Structural Equation Modeling) untuk mengetahui keberadaan variabel laten yang merupakan variabel yang tidak dapat diukur secara langsung. Penelitian ini menggunakan desain penelitian cross sectional sehingga hanya dapat menunjukkan kejadian pada satu waktu saat dilakukan penelitian saja. Di waktu yang berbeda, sampel yang digunakan mengalami perubahan dalam berbagi pelatihan maupun kompetensi individual yang bisa memberikan pengaruh yang berbeda. Bagi penelitian selanjutnya, disarankan peneliti menggunakan metode longitudinal agar hasil penelitian dapat lebih baik dan akurat serta objektif sehingga dapat digeneralisasi.

\section{REFERENSI}

Amirullah. 2013. Metodologi Penelitian Manajemen: Disertai Contoh Judul Penelitian dan Proposal (cetakan pertama). Malang: Bayumedia Publishing.

Ayu Salmah, Ninin Non. 2012. Pengaruh Program Pelatihan dan Pengembangan Karyawan Terhadap Kompetensi Karyawan pada PT. Muba Electric Power Sekayu. Jurnal Ekonomi dan Informasi Akuntansi (Jenius), 2(3), 278-290.

Darmawan, Deni. 2013. Metode Penelitian Kuantitatif (cetakan pertama). Bandung: PT Remaja Rosdakarya.

Der Merwe, John Van., and Sloman, Martyn. 2014. Training the Trainer - Lessons from the new South Africa. Higher Education, Skills and Work-Based Learning, 4(1), 17-30. Retrieved from Emerald Insight.

Dirani, Khalil M. 2012. Professional Training as A Strategy for Staff Development: A Study in Training Transfer in the Lebanese Context. European Journal of Training and Development, 36(2/3), 158-178. Retrieved from Emerald Insight.

Edison, Emron. 2009. Human Resource Development. Bandung: Alfabeta.

Fedderke, J.W. 2005. "Technology, Human Capital and Growth". Paper on School of Economics, University of Cape Town, South Africa.

Hasibuan, Malayu S.P. 2007. Manajemen Sumber Daya Manusia (cetakan kesembilan). Jakarta:
PT Bumi Aksara.

Indrawan, Rully dan Yaniawati, R. Poppy. (2014). Metodologi Penelitian: Kuantitatif, Kualitatif dan Campuran untuk Manajemen, Pembangunan dan Pendidikan (cetakan pertama). Bandung: PT Refika Aditama.

Indrawati. 2015. Metode Penelitian Manajemen dan Bisnis (Konveksi Teknologi Komunikasi dan Informasi). Bandung: Refika Aditama.

Kambey, Fendy Levy dan Suharnomo, Suharnomo. 2013. Pengaruh Pembinaan, Pelatihan dan Pengembangan, Pemberdayaan dan Partisipasi Terhadap Kinerja Karyawan, Jurnal Studi Manajemen dan Organisasi, 10(2), 142-151. Retrived from ejournal.undip.ac.id

Kandou, Erlin Emilia. 2013. Pengaruh Pelatihan dan Pengembangan Karyawan terhadap Produktivitas Kerja Karyawan (Studi pada PT. Air Manado), 2(3). Retrived from ejournal.unsrat.ac.id

Korytova, Elena., Zandanova, Olga., Chukreeva, Larisa., Radnaeva, Evgeniya., and Yabzhanova. 2015. Competency-Based Approach to Training Humanities Students at East Siberia State University of Technology and Management. Worldwide Trends in the Development of Education and Academic Research, 214, 271278. Retrieved from Procedia Social and Behavioral Sciences.

Lombardi, Mollie and Laurano, Madeline. 2013. Human Capital Management Trends 2013: It's a Brave New World [online]. www.aberdeen. com. [September 2015].

Marwansyah. 2010. Manajemen Sumber Daya Manusia (edisi kedua). Bandung: Alfabeta.

Merdeka Online. 2015. Menghadapi MEA 2015 Indonesia Masih Kekurangan Tenaga Profesional. [Online].http://www.merdeka online.com/berita-5744-menghadapi-mea-2015indonesia-masih kekurangan-tenaga-profesional. html [September 2015]

Mulyatiningsih, Endang. 2012. Metode Penelitian Terapan Bidang Pendidikan (cetakan pertama). Bandung: Alfabeta.

Naweed, Anjum and Abrosetti, Angelina. 2015. Mentoring in the Rail Context: The Influence of training, style and practice. Journal of Workplace Learning, 27(1), 3-18. Retrieved from Emerald Insight.

Nilsson, Annika and Engstrom, Maria. 2015. Eassessment and e-Training Program among Elderly Care Staff Lacking Formal Competence: Result of a Mixed-Methods Intervention 
Study. [online]. www.biomedcentral.com. [September 2015].

Noor, R. Zulki Zulkifli. 2012. Manajemen Sumber Daya Manusia. Yogyakarta: CV Budi Utama.

Olsen, Dag H., and Eikebrokk, Tom R. 2009. Training, Competence, and Business Performance: Evidence from e-Business in European Small and Medium-Sized Enterprises. International Journal of e-Business Research, 5(1), 92-116. Retrieved from IGI Global.

PB, Triton. 2010. Manajemen Sumber Daya Manusia: Perspektif Partnership dan Kolektivitas (cetakan pertama). Jakarta Selatan: ORYZA.

Poniman, Farid dan Hadiyat, Yayan. 2015. Manajemen HR: Terobosan untuk Mendongkrak Produktivitas. Jakarta: PT Gramedia Pustaka Utama.

Priansa, Donni Juni. 2014. Perencanaan dan Pengembangan Sumber Daya Manusia. Bandung: Alfabeta.

PT Len Industri (Persero). 2015. [online]. http:// www.len.co.id/ [September 2015]

Qodriah, Sari Laelatul. 2012. Manajemen Sumber Daya Manusia. Yogyakarta: CV Budi Utama.] epublik Indonesia. 2003. Undang-Undang No.13 Tahun 2003 tentang Ketenagakerjaan. Sekretariat Negara. Jakarta.

Riduwan dan Kuncoro, Engkos Achmad. 2012. Cara Menggunakan dan Memakai Analisis Jalur (Path Analysis). Bandung: Alfabeta.

Rivai, Veithzal dan Sagala, Ella Jauvani. 2011. Manajemen Sumber Daya Manusia untuk Perusahaan (edisi kedua). Jakarta: PT RajaGrafindo Persada.

Sandjojo, Nidjo. 2011. Metode Analisis Jalur dan Aplikasinya (cetakan pertama). Jakarta: Pustaka Sinar Harapan.

Sanusi, Anwar. 2011. Metodologi Penelitian Bisnis. Jakarta Selatan: Salemba Empat.

Sarwono, Jonathan. 2007. Analisis Jalur untuk Riset Bisnis dengan SPSS. Yogyakarta: C.V Andi Offset.

Sekaran, Uma. 2006. Research Methods for Business (cetakan keempat). Jakarta: Salemba Empat.

Setyaningdyah, Endang.,Kertahadi, Umar Nimran., dan Thoyib, Armanu. 2013. The Effects of Human Resource Competence, Organisational Commitment and Transactional Leadership on Work Discipline, Job Satisfaction and Employee's Performance. Interdisciplinary Journal Of Contemporary Research In
Business, 5(4), 140-153. Retrieved from Institute of Interdisciplinary Business Research. Sinollah. 2008. Pengaruh Pelatihan yang Efektif Terhadap Kepuasan Kerja Karyawan KSP. Tunas Artha Mandiri Cabang Tuban. Jurnal Otonomi, 8(1), 121-130. Retrived from researchgate.net

Subekhi, Akhmad dan Jauhar, Mohammad. 2012. Pengantar Manajemen Sumber Daya Manusia (MSDM). Jakarta: Prestasi Pustakaraya.

Sudarmanto. 2009. Kinerja dan Pengembangan Kompetensi SDM: Teori, Dimensi Pengukuran dan Implementasi dalam Organisasi (cetakan pertama). Yogyakarta: Pustaka Pelajar.

Sugiyono. 2013. Metode Penelitian Kuantitatif, Kualitatif dan $R \& D$ (cetakan kesembilan belas). Bandung: Alfabeta.

Sunarta. 2008. Perencanaan Sumber Daya Manusia: Kunci Keberhasilan Organisasi. Dosen Luar Biasa Jurusan Manajemen FISE Universitas Negeri Yogyakarta: Manajemen Pendidikan, No. 01/Th IV/April/2008.

Sunyoto, Danang. 2012. Manajemen Sumber Daya Manusia. Yogyakarta: CAPS (Center for Academic Publishing Service).

Sutrisno, Edy. 2009. Manajemen Sumber Daya Manusia (edisi pertama). Jakarta: Kencana.

Suwatno, H dan Priansa, Donni Junni. (2011). Manajemen SDM dalam Organisasi Publik dan Bisnis (cetakan kedua). Bandung: Alfabeta.

Syam, Alphieza. 2015. Menepis Paranoid MEA 2015. SWAOnline. [Online]. Tersedia: http:// swa.co.id/column/menepis-paranoid-mea-2015 [September 2015]

Umar, Husein. 2008. Metode Penelitian untuk Skripsi dan Tesis Bisnis (Edisi 2). Jakarta: PT. Raja Grafindo Persada.

U.S., Supardi. 2013. Aplikasi Statistika dalam Penelitian: Konsep Statistika yang Lebih Komprehensif (cetakan kedua). Jakarta Selatan: Change Publication.

Vermeulen, Joeri., Becckman Katrien., De Clercq, Gerlinde., Vandelannoote, Isabelle., Gucciardo, Leonardo, and Laubach Monika. 2016. Interprofessional Perinatal Simulation Training: A Valuable Educational Model to Improve Competencies amongst Student Midwives in Brussels, Belgium. Elsevier, 33, 49-51. Retrieved from Midwifery. 
Voegtlin, Christian., Boehm, Stephan A., and Bruch Heike. 2015. How to Empower Employees: Using Training to Enhance Work Units Collective Empowerment. International Journal of Manpower, 36(3), 354-373. Retrieved from Emerald Insight.

Wardhana, Aditya. 2014. Manajemen Sumber Daya Manusia. Bandung: PT Karya Manunggal Lithomas.
Zuana, Citra Indah., Swasto, Bambang., dan Susilo, Heru. 2014. Pengaruh Pelatihan Kerja dan Lingkungan Kerja Karyawan Terhadap Prestasi Kerja Karyawan (Studi pada karyawan PT. Jamsostek (Persero) kantor cabang Malang), 7(1). Retrieved from Jurnal Administrasi Bisnis (JAB) administrasibisnis. studentjournal.ub.ac.id 